\title{
DEVELOPMENT IMPETUS FOR TESOL PRACTITIONERS: A REVIEW OF THE LITERATURE AND RECOMMENDATIONS FOR ANDRAGOGICAL FRAMEWORKS
}

\section{Jesse Jones Richter}

\begin{abstract}
This review of the literature acknowledges and describes current states of training amongst professional members of the global English language learning industry. Particular attention is given to the design and implementation of professional development programs for English language instructors in order to inform the harvest of qualitative data from an Action Research project at Kyungpook National University in Daegu, South Korea. Three brief case studies of Jordan, Colombia and South Korea serve to ground research inquires across world regions. Findings suggest a need for stronger in-service professional development training programs, more culturally-responsive programmatic orientations, and more formalized training curricula. Finally, this paper articulates recommendations for developing an improved andragogical framework which may then be adopted across schools and cultures.
\end{abstract}

Keywords: Professional Development, English Language, TESOL, Action Research, Pedagogy, Andragogy, South Korea, Globalization 